\title{
Article
}

\section{Phenomenology as a political position within maternity care}

Thomson, Gillian and Crowther, Susan

Available at https://clok.uclan.ac.uk/29220/

Thomson, Gillian orcid iconORCID: 0000-0003-3392-8182 and Crowther, Susan (2019) Phenomenology as a political position within maternity care. Nursing Philosophy, 20 (4). e12275. ISSN 1466-7681

It is advisable to refer to the publisher's version if you intend to cite from the work. http://dx.doi.org/10.1111/nup.12275

For more information about UCLan's research in this area go to http://www.uclan.ac.uk/researchgroups/ and search for < name of research Group>.

For information about Research generally at UCLan please go to http://www.uclan.ac.uk/research/

All outputs in CLoK are protected by Intellectual Property Rights law, including Copyright law. Copyright, IPR and Moral Rights for the works on this site are retained by the individual authors and/or other copyright owners. Terms and conditions for use of this material are defined in the policies page.

\section{CLoK}

Central Lancashire online Knowledge www.clok.uclan.ac.uk

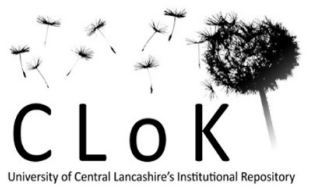


1 Phenomenology as a political position within maternity care

2

3 Abstract

4

5

6

7

8

9

In this article the authors use the context of childbirth to consider the power that is endemic in certain forms of evidence within maternity care research. First, there is consideration of how the current evidence hierarchy and experimental-based studies are the gold standard to determine and direct women's maternity experiences, although this can be at the detriment of care and irrespective of women's needs. This is followed by a critique of how the predominant means to assess women's experiences via satisfaction surveys is of limited utility, offering impartial and restricted insights to assess the quality of care provision. A counter position of hermeneutic phenomenology as research method is then described. This approach offers an alternative perspective by penetrating the taken-for-granted ordinariness of an event (such as childbirth) to elicit rich emic meanings. While all approaches to understanding maternity care have a place, depending on the question(s) being asked, the contribution of phenomenology is how it can uncover a depth of contextual understanding into what matters to women and to inform and transform care delivery.

Key words: hermeneutic phenomenology, evidence-based medicine, satisfaction surveys, maternity care

\section{Introduction}

The world of maternity care and childbirth invokes passion for most. Childbirth is a liminal, powerful experience which can have short and long-term negative or positive experiences for women, their infants and families. Whilst it is crucial that childbirth is a positive experience, the how, what and why of research into various elements of the maternity world have become political. From an etymological perspective, the term political has varying definitions. It can concern a process of negotiation to enable individuals to achieve important human goals. Or from a more derogatory perspective, it relates to exertions of power to achieve dominion over the 'other'. In this article, both perspectives are considered in relation to the use of evidence within a maternity care context. In the following sections, the premise and reality of the evidence-based medicine (EBM) movement is outlined. While EBM was originally conceived to inform care decisions based on best available evidence, intuition and patient needs, it has been criticised for its rule-based approach that uses population (statistical) norms, rather than 
individualised, dynamic care provision. A situation which has the potential for pervasive and negative implications. The paradigm that espouses EBM also seeks to understand women's experiences and their care via satisfaction surveys. While such an approach is helpful in drawing attention to general common themes, surveys offer little utility to understand and appreciate how maternity care is experienced. Phenomenology as research method on the other hand enables in-depth access to understanding individual's context-related realities; to generate rich lived accounts that can inform care decisions and to direct needs led care. In general, most other methodologies focus on explanation, causations and building theories. Phenomenology is concerned with description and interpretation, drawing out meaning from the data that can resonate with others. As van Manen (2014) affirms phenomenological inquiry 'directs its gaze towards the regions where meanings and understandings originate, well up, and percolate through the porous membranes of past sedimentation - then infuse, permeate, infect and exercise a formative and affective effect on our being' (p. 26-27).

In this article the politics inherent in numerical based methodologies and phenomenological approaches are highlighted. The dominance of scientific approaches within maternity care can mean that population-based, rather than individualised care is provided and women's voices can be silenced. The key contention is that while different research questions require different approaches to further understanding, when aiming to understand, inform and improve maternity care based on what matters most, then phenomenological based research is a valuable option.

\section{The premise and reality of evidence-based medicine}

Evidence based medicine (EBM) is a key tenet of modern healthcare. While originally EBM was conceived to teach the practice of medicine, it expanded to an approach to optimise decision-making by using the best available evidence to inform clinical care (Greenhalgh, Howick \& Maskrey, 2014). In line with the current evidence hierarchy, with different types of evidence classified on its epistemological strength, the best available evidence stems from meta-analyses, systematic reviews and randomised controlled trials. With this evidence subsequently used to inform the design of guidelines, such as those devised by the World Health Organisation (WHO) or the National Institute of Health and Clinical Excellence to 'regulate the quality of medical practice' (Weisz, Cambrosio, Keating, Knaapen, Schlich \& Tournay, 2007, p. 692). Guidelines are defined by the Institute of Medicine (2011) as 
'statements that include recommendations intended to optimize patient care that are informed by a systematic review of evidence and an assessment of the benefit and harms of alternative care options' (p.1).

EBM was designed to move away from a highly subjective, lay approach to healthcare, to one that was grounded in verified evidence. Until its introduction, the extent to which research was incorporated into clinical decision-making was implicit, informal and idiosyncratic (Weisz et al, 2007). EBM therefore aimed to make decision-making more structured and objective by better reflecting the available evidence (Grobbee \& Hoes, 2009; Katz, 2001). Greenhalgh et al (2014) describes EBM as an 'energetic intellectual community commitment to making clinical practice more scientific and empirically grounded and thereby achieving safer, more consistent and more cost effective care' (p. 1). Key successes of the EBM movement include the establishment of the Cochrane Collection that produces high-quality systematic reviews and other synthesised research evidence; devising standards to develop and update guidelines; developing standards and resources for critical appraisal, methodological and publication standards and knowledge translation (Greenhalgh et al, 2014). It is important to consider however that the EBM movement as originally conceived was not designed to make decisions on evidence per se, but rather as espoused by David Sackett and colleagues (1996) as:

'the conscientious, explicit and judicious use of the current best evidence in making decisions about the care of the individual patients. The practice of evidence based medicine means integrating individual expertise with the best available external clinical evidence from systematic search...Good doctors use both individual clinical expertise and the best available external evidence and neither alone is enough. Without clinical expertise, practice risks becoming tyrannized by external evidence' (p.1)

This position stipulates how EBM relates to the use of guidelines (based on population-based data, such as that derived through meta-analyses of the experimental literature) as well as the expertise of the clinician, and the rights, and preferences of the individual patient to inform care decisions (Doi, 2012; Sackett, Rosenberg, Gray, Haynes \& Richardson, 1996). Therefore, while EBM advocates that decisions and policies should be based on evidence, and not just the beliefs of practitioners, there is a concomitant call that decision-making needs to be more of a nuanced, intuitive and evidence informed exercise. EBM thereby emphasizes two positions. 
First, while clinical guidelines are based on population level data, with little opportunity for modification by individual practitioners, the underpinning evidence needs to be high quality and to demonstrate the test's or treatment's effectiveness (Eddy, 1990; Greenhalgh et al, 2014). Second in relation to individual decision-making, EBM is designed to give practitioners greater autonomy in combining their clinical judgement when interpreting the research evidence (Greenhalgh, Snow, Ryan, Rees \& Salisbury, 2015; Sackett et al, 1996). EBM thereby represents an umbrella level term for an emphasis on evidence in both population-level and individual-level decisions. While the uptake of EBM within a maternity care context was slow, some successes concern more appropriate and sophisticated treatments for women with preexisting health morbidities such as diabetes and cardiac complaints (Enkin, 2006). EBM has been responsible, through identifying a lack of evidence, for changes to a number of unnecessary care practices, such as perineal shaving (Basevi \& Lavender, 2014), over use of cardiotocography (monitoring the fetus in labour) (Alfirevic, Gyte, Cuthbert \& Devane, 2017) and routine use of enemas (Reveiz, Gaitán \& Cuervo, 2013).

While EBM is heralded as the 'gold standard' of clinical practice, there are a number of criticisms and limitations of its use (Greenhalgh et al, 2014; Straus \& McAllister, 2000; Timmermans \& Mauck, 2005). First, the best quality evidence that underpins evidence-based guidance - RCTs - face many criticisms. These criticisms include trialists recruiting participants who are most likely to be responsive to treatment, thereby producing effects suitable for 'average' rather than individual patients (Greenhalgh et al, 2014, 2015; Krauss, 2018; Wieringa, Engebretsen, Heggen \& Greenhalgh, 2017) together with the fact that certain populations are notoriously under-researched (e.g. black and minority ethnic populations, complex needs) (Krauss, 2018; Rogers 2004). Negative trial results can be suppressed, and studies not replicated, even when contradictory results exist (Greenhalgh et al, 2014; Ioannidis, 2005). There are also biases of corporate industries (e.g. drugs/medical devices) determining which treatments or tests should be subjected to experimental testing (Greenhalgh et al, 2014). Further issues relate to the quality of available evidence, such as studies being insufficiently, or over powered and how reliance on the p value (i.e. 0.05) to determine significance can lead to false negatives or false positives (Ioannidis, 2005; Krauss, 2018); this in turn can mean that some of the influential studies used to determine care are misleading (Ioannidis, 2005; Greenhalgh et al, 2014). Another key challenge relates to how healthcare providers do not follow the evidence, which in part relates to the plethora of available evidence. A study by 

in a healthcare area were being published per day, as well as how a plateau had not yet been attained. While this can mean that clinical guidelines are in danger of being out of date, a further difficulty relates to how professionals are biased towards particular approaches - even when evidence is indisputably against a particular form of treatment, it can take some time before other treatment modalities are preferred (Epstein, 2017).

EBM was initially conceived as an approach in which evidence should be used alongside the subtleties of clinical judgement and patients' needs and preferences (Greenhalgh et al, 2014). However, in practice the evidence can be used injudiciously, with guidelines and algorithmictype decision tools adopted as rules to direct care, thereby crowding out patient's clinical and personal idiosyncrasies (Greenhalgh et al, 2014, 2015; Mullen \& Streiner, 2004; Rogers 2004). There are also concerns that inexperienced clinicians may be unable to judge or assess the evidence or apply judgement in unique cases (Weisz et al, 2007). An overuse of guidelines reflects fears of litigation, whereby close adherence offers the means to safeguard professional practice (Berg, 2000; Weisz et al., 2007). As litigation claims for maternity services were $£ 3$ billion+ over the period 2000-2010, blanket adherence may appear advisable (Anderson, 2013). Greenhalgh and colleagues (2014) argue how contemporary healthcare's 'complex economic, political, technological and commercial context has tended to steer the evidence-based agenda towards population, statistics, risk and spurious certainty’ (p. 5).

The negative implications of a scientific, population, rule based, rather than person centred approach on women's birth experiences is well reported in the literature. For example, there have been reports of how the clinical management of women's bodies, serves to objectify and cause harm through mistreatment (Bohren, Vogel, Hunter, Lutsis, Mahk, Souza, et al, 2015; Thomson \& Downe, 2008), abuse and cultural insensitivity (Kitzinger, 2005), disempowerment and degrading treatment (Wolf, 2001) over medicalization and gross inequalities among women globally and the unavailability of resources when required (Miller, Abalos, Chamillard, Ciapponi, Colaci \& Comandé et al, 2016). What women want and need experientially is often not what is locally available (Downe, Finlayson, Tuncalp \& Gülmezoglu, 2016). Ironically, it appears that women’s experiences are often not the priority in maternity research which is focused on women's reproduction. Women's experiences have perhaps been lost and hidden in research agendas that privilege a reductionist world view 
attuned to empiricism and scientism, such as assessing women's experiences of care via satisfaction studies.

\section{The limitations of satisfaction}

Whilst women's views are frequently divorced from maternity and childbirth research one of the main ways in which their responses/experiences of care is assessed is via satisfaction surveys. But are these able to reach into the meaning and significance of childbirth? After all the maternity system and all its technology and 'know how' are a small aspect of the journey of a woman, family and community. The childbirth year is infused with many experiences, myriad impressions and potential for personal and collective transformation (Crowther, 2017). While some argue that satisfaction is a proxy to assess the success of professionals or hospitals treatment and care (Prakash, 2010), others perceive such methods as platitudinous and meaningless. There is a certain arrogance in assuming that empirical researchers can access what a good or satisfactory childbirth experience is or is not. Some researchers and authors have attempted to unpack these complex notions and conclude that it is important to always remain open to new understandings because any attempt to provide a general final definition is untenable (Smythe, Hunter, Gunn, Crowther, McAra Couper, Wilson et al, 2016).

Satisfaction surveys, as is the evidence underpinning the EBM approach, are situated within a positivist epistemology. This is an approach that advocates how an object of inquiry (e.g. satisfaction) can be independently measured by an independent observer - thereby controlling what will be studied, what counts as some property of the object and how such evidence can be understood. In the positivist paradigm what is sought is the absolute truth (Mantzoukas, 2004). Such approaches remove subjects from the context of the situation and assumes that entities can be is broken down into discrete isolated units to make orderly assumptions about the units. These units are then re-constructed to formalise an organised picture of nature (Plager, 1994). Thus, in satisfaction surveys of maternity care, women are asked to 'score' their experiences against a series of predetermined quality indicators, whilst insights into their lived accounts of what matters is not considered. There are a number of key debates about the utility of satisfaction studies that can be classified into three key areas; definition, measurement and validity. 
In relation to definition - satisfaction is generally perceived to be a highly individual, subjective and multifaceted concept which is difficult to define (Bramadat \& Driedger, 1993; Sitzia \& Wood, 1997; Simon, Johnson \& Liddell, 2016); with these problems largely relating to the different indices of this construct. In a maternity related context for instance, Green, Coupland \& Kitzinger (1990) identified four maternal outcomes ('satisfaction', 'fulfilment', 'emotional wellbeing' and 'description of babies') as being related to different variables and labour experiences. In contrast, Salmon \& Drew (1992) identified three key independent dimensions of childbirth, namely 'fulfilment/delight', 'distress/displeasure' and 'pain/difficulty of childbirth'. A more recent review identified nine questionnaires of satisfaction with care during labour and birth that were generally not based on theoretical models of satisfaction, i.e. fulfilment or discrepancy theories (Sawyer, Ayers, Abbott, Gyte, Rabe \& Duley, 2013). Further complications relate to how surveys tend to measure what the researcher(s) rather than what women perceive to be important, with satisfaction perceived to be a 'lukewarm' concept that fails to describe the 'delight', 'ecstasy' and 'relief' towards childbirth (Proctor, 1999, p. 495).

A key difficulty when measuring satisfaction is that high levels of satisfaction tend to be recorded towards any given question. A lack of variability in responses is a longstanding debate as to the ability of surveys to discriminate between, and within, population groups. The finding that respondents tend to adopt a positive skew when answering questions on satisfaction, or 'faking good' by answering questions to please the administrator are recurring issues (Choi \& Pak, 2005). Women may not want to express dissatisfaction due to social desirability or fear of reprisal (Choi \& Pak, 2005; Prakash, 2010), particularly if women plan to become pregnant again and to re-engage with current maternity services. This bias may also be magnified if women are asked to make evaluations whilst still in the maternity environment.

In regard to the final area of debate - validity - general satisfaction surveys face criticisms due to being poorly constructed and to have poor psychometric properties such as validity and reliability (Sawyer et al, 2013). Survey methodologies remove the subjects from the context of the situation, and the forced-choice methods are unable to do justice to the range and complexity of the human feelings involved. For instance, maternity satisfaction surveys may include questions in relation to women's perceptions of control. While control is repeatedly identified as a central facet in determining women's subjective responses to childbirth (e.g. 
Elmir, Schmied, Wilkes \& Jackson, 2011), quantitative driven responses offer little insights into why women felt out of control, who was involved, how it happened and the impact of such (Thomson \& Downe, 2008).

Within satisfaction surveys the possibilities for alternatives get covered over and this poses the risk that something of significance becomes lost, forgotten and ignored. For instance, a recent satisfaction survey undertaken in Scotland completed by less than half the intended population found that only $56 \%$ women were satisfied with not knowing the midwife who cared from them in labour and birth (Scottish Government, 2019). However, there is a plethora of research that highlights that it is continuity of relational care by a known midwife (or small group of known midwives) that is desired, (e.g. Dahlberg \& Aune, 2013; Homer, Brodie, Sandall \& Leap, 2019; Sandall, Soltani, Gates, Shennan \& Devane, 2016) rather than an organisation of care providing a continuum of information and interventions. Using this as a case example raises key questions concerning validity of the Scottish survey results. First, how can study participants respond to a question about an experience they may have never encountered (a known midwife in Scottish maternity was relatively rare at the time of the survey), and second, the women's satisfaction score does little to illuminate what exactly women were satisfied about. What is concerning is the potential for such a national survey to inform health policy that could be contrary to what actually matters.

While satisfaction surveys can point to positive and negative areas of practice, these methods are unable to access deep and meaningful data that foregrounds contextually rich experiences as lived in and lived through. This poses the question 'What is an effective methodological approach to reveal and understand maternity satisfaction?' A seemingly innocent question that can and often does have political ramifications.

\section{Politics of phenomenology as research method}

There are ongoing debates about the merits of qualitative and quantitative research methodologies. Qualitative methods aim to elicit the underlying reasons, opinions, and motivations of a given phenomenon (Bryman, 2016); to research the many why and how questions of human experience (Crotty, 1996). While statistical based approaches play an invaluable role in determining 'what works', as highlighted earlier, such approaches are not infallible and can generate misinformed interpretations (Spiegelhalter, 
2019). Although numbers themselves are unable to lie, as highlighted above, they can (as indeed can all forms of evidence) be used in ways that obscure, confuse or even mislead. Quantitative data is not a sufficient method of inquiry to understand the quality and depth of human experiences, at least not on its own. If the intention is to gather in-depth and meaningful data to understand, inform and shape care delivery, then hermeneutic phenomenology is a valuable option. Hermeneutics and phenomenology are terms that are often conflated. In brief, phenomenology is focused on lived experiences. Hermeneutics in its most basic definition is concerned with textual interpretation and acknowledges that human beings are always interpreting (Gadamer, 1967/2008). Thus, hermeneutic phenomenology is interpretation of textual data that describes lived experiences of a 'world'. The purpose of the phenomenological project is to penetrate the taken-for-granted ordinariness of an event (such as childbirth) and surface the pre-reflective meanings that lay behind the theories, systems, protocols and concepts of that world. To do this, phenomenologists often use deep, rich and meaningful data captured via face to face dialectical open interviewing, a stance congruent with other qualitative research designs (e.g. Crouch \& McKenzie, 2006; Kvale \& Brinkman, 2009; Patton, 2014).

Although hermeneutic phenomenology is similar in many ways to other qualitative methodologies the philosophical underpinnings of this approach demand a rigorous level of soul-searching reflexivity and an appreciation of seminal philosophical texts with an ability to think, write and remain open to unknown possibilities - it is an exacting journey. As a research method hermeneutic phenomenology challenges the purely empirical approach and endorses a naturalist ontology wherein nature and culture come together (van Manen, 2014). While the current evidence hierarchy (Greenhalgh, 1997) does not include qualitative approaches, hermeneutic phenomenology incorporates both the externalized standpoint/representation as well as the subjective. The distinction between what is objective and subjective are deconstructed through the philosophical and Heideggerian notions of Dasein and being-in-theworld (Heidegger, 1927/1962). These central notions that underpin hermeneutic phenomenological research overturn the positivistic view of a subject (e.g. researcher) examining an object (e.g. satisfaction).

If one is to take Heidegger's notion of Dasein as the starting point for all human inquiry, then both studies with numbers-quantitative and words-qualitative are without hierarchical value. 
Dasein or 'being-in-the-world' are all of that same world, with no arbitrary divisions. There is no subject and object. Being-in-the-world is concerned with a referential totality that does not just imply relationships between entities of the world that can include and exclude each other, it is also about how humans project their perceptions and way of existing into that world that opens a clearing within which they can be (Heidegger, 1971/2001). Human beings and world are one and the same, which from a researcher perspective means that they are inseparable from who they are as researchers, to the world in which they investigate. This philosophical positioning understands all study participants as part of a contextual world from which they can never be separated out from, put another way, participants are the world that they live and experience their lives. As Heidegger contends a world 'worlds' (1927/1962). This implies that researchers have responsibility to always remain open to the myriad contextual realities of their research domains.

A primary intention of hermeneutic phenomenological research is not to elicit a 'truth' but rather to broaden horizons of understanding and reveal that which is within and beyond the taken-for-granted everyday experience (e.g. experiences of satisfaction, or not, in maternity) and not simply measure and describe what is already materially there (Gadamer, 1967/2008). Heidegger would tell us to be cautious about falling blindly and unquestionably into the ontic (material) debates and discourses that attune an epoch favouring numbers over experiential data and ontological insights (Heidegger, 1927/1962). He would argue that to do so is inauthentic. In this sense this is concerned with individuals having their vision denuded by the allure of scientism's promise of fixed final solutions. Heidegger raised concerns about the use of technology in modern society (including research methodologies) (Heidegger, 1977). Heidegger was not concerned with the instrumental value of technology, but rather its essence. This related to how scientific, calculable, technical know-how, such as the injudicious use of evidence and blanket adoption of satisfaction, was becoming the main means through which human beings understand and interpret their life-worlds. Heidegger conceived the dominion of technological thinking to be leading to a 'darkening of the world' via an ever increasing abandonment of individuality and intuition (Heidegger, 1977). While human beings may be thrown into this epoch of scientism's gaze, researchers who use hermeneutic phenomenology seek a different approach to their research endeavours that call for an attunement of wonder and openness. This move is eloquently described by Eugene Kaelin (1988): 
'To get out of the maze that is not of our own construction but into which we are thrown as surely as the rats in the psychologist's maze, we must be able to modify our behaviour. If living in the world of the other, by the other's rules, is an essential structure of individual existence, then to be oneself, a different form of behaviour is indicated......Being a true self, being one's self truly, is such a creative projection' (p.97).

This calls upon the hermeneutic phenomenologist to challenge contemporary research behaviours that expects objectivity, and which necessitates a degree of personal and professional exposure. Given that human beings are always, in some way, thrown into a world that is interpreted from an individual's historical basis of understanding, it is important to inform the reader of the researcher's unfolding interpretive understanding. A failure to disclose the researcher's inherent biases can be detrimental to the rigor and trustworthiness of any research design, both qualitative and quantitative. Prioritising reflexivity is a methodological strength in hermeneutic phenomenology (Crowther, Ironside, Spence \& Smythe, 2016; Smythe, 2011). This ensures that the researcher works with integrity by applying a radical and critical self-reflective stance throughout a project wherein preunderstandings are acknowledged and foregrounded. Thus, preunderstandings are neither concealed nor claimed to be bracketed out, rather they are understood as part of the interpretive process. Gadamer (2008) contends that it is the researcher's judgements and pre-understandings that are central to inquiries because they lead to what is questioned. This stance directly challenges many other research methods that favour critical objectivity.

Equally significant is the reluctance of hermeneutic phenomenological researchers to claim any generalisability in their studies because this would infer that if certain variables in another context were the same or similar, then the effect would be the same. From an orientation that seeks general findings to an orientation that seeks outcomes that favour the individual experience but can inform quality for everyone can challenge the status quo. The constant drive to produce generalisable findings can bring into question the utility of research that does not seek or claim generalisability. This orientation occurs whilst staying constantly mindful that the hermeneutic phenomenological gaze does not attune to ideas of proving or/and cause - as effect outcomes only serve to limit an understanding of what it means to be human. Where 
many researchers see causes, those aligned with hermeneutic phenomenology see complex impacts in which ever deeper understandings are waiting to be illuminated.

Hermeneutic phenomenology as research method has become contested and confronted by a variety of political and methodological challenges about what research is and is not. Specifically, the trustworthiness of the research designs and interpretive analysis. Paradoxically it is the acceptance of this difficulty in capturing the phenomenon of human life, the rigorous pursuit of reflexivity, and use of first person prose in phenomenological based studies that attracts most resistance in the research community. Such resistance is reflected in how phenomenological researchers are accused of being overtly subjective, lacking objectivity, and how their work adds little value to the knowledge of complex human experiences and situations (Paley, 2005, 2016). However, there has been recent moves in the use of phenomenological based research being utilised within health professional training in maternity care. For instance, within the Royal College of Obstetrics and Gynaecology's online training platforms, some courses provide evidence' (from qualitative and quantitative based studies), first party stories based on real life accounts of individual women, and reflective questions to instil knowledge and invoke change. A recent study by Jennifer Patterson used a phenomenological based method to collect lived experiences of women and maternity care providers. This study identified that one of the main issues related to women experiencing a difficult birth was poor communication and interactions with healthcare providers. It also found that maternity staff face conflicts in trying to provide a midwifery model of care based on connection, trust and reciprocity while working within a maternity institution that is dominated by risk and surveillance (Patterson, 2018, 2019). Rather than just report the findings within a thesis or publications, she used the evidence to create a film in which trained actors used the medium of expressive dance to depict the discord in providing woman-centred care. This film has been played at numerous academic and professional based venues to raise awareness and invoke change. A similar approach has also been adopted by Stephanie Heys (2018) whereby women's lived accounts of maternity care were used to identify the key interpersonal triggers of birth trauma to develop a script that was filmed using professional actors from a first party 360-degree perspective. This film was then shown to maternity professionals using virtual reality headsets within a tailored education programme. The aim being that the immersion of maternity professionals within a real-life scenario would facilitate emancipatory praxis. These examples highlight how rich, powerful, interconnected lived 
accounts collected via phenomenological based methods can be used for political gains in raising awareness amongst healthcare providers and reconnecting them to the human aspects of caring.

The examples above highlight how phenomenological based research can inform healthcare practice in ways that are often surprisingly simple, yet often unspoken and hidden. Moreover, the world of maternity research is always being interpreted and thus becomes one of many ways of being in that world. The risk of privileging one research approach over another leaves health and social care research deficient. However, it is evident that there are social and political oppositions to doing hermeneutic phenomenological research in a world where the positivist lens is favoured. Despite three decades of growth in the expertise and quality of qualitative research the positivist discourse continues to dominate the research world, especially in health care (Patton, 2014). Although it is important to acknowledge that there has been a shift in the acceptance of qualitative approaches and asking questions that are experientially orientated and not solely numerically focused (Kennedy, Cheyney, Dahlen, Downe, Foureur, Homer et al, (2018); a recent example is the inclusion of qualitative findings in WHO global guidance for maternity care (WHO, 2018). Despite this growing acceptance and appreciation of phenomenological based research, researchers have encountered continuing challenges, inequalities, and inequities, which manifest in academic research careers, funding opportunities, authorship of papers, editorial and reviewer preferences (publications and conferences), post graduate research supervision and ethics applications. This often entails this genre of research being underfunded and resource poor. Researchers, practitioners, commissioners and policy makers need to remain open and accepting that different questions require different approaches to further understanding.

\section{Conclusion}

Qualitative and quantitative approaches are not merely tools for application that are 'fit for purpose'; rather their adoption reflects a fundamentally different value-base, approach and interpretation of meaning. However, to privilege one over another is a political act. The core of business of researchers is to seek answers to the questions they pose. In the current epoch, quantitative based studies represent authoritative ways of knowing with generalisable outcomes based on large numerical data sets holding dominion over individual needs and perspectives. The stripping of context from the realities of health care, such as via maternal 
satisfaction surveys, leaves the evidence bereft of deeper understanding and the value of human experience whittled down into a commodity, a one size fits all; a situation that perhaps reflects neoliberal approaches to contemporary party politics and resultant health care policy.

Hermeneutic phenomenological researchers attune differently to their research projects when compared to those who operate within a positivistic realm. Researchers orientate towards an alternative ontology that does not adhere to object and subject divisions of the world. This speaks to an openness so that phenomenon, such as what counts in maternity care is set free to show itself. Researchers can access a world (e.g. childbirth) by capturing lived accounts, and through which the lived in and lived through interconnected relational totality of experiences can be realised. The recent move towards using phenomenological based research within innovative education and learning opportunities demonstrate the politics of this method to negotiate and transform maternity care.

As researchers, the primary action in initiating any research is asking 'What type of research questions are we asking? and 'For whom are we asking the question?' This recognises and foregrounds that any research is always embedded in the social and political environment. It is the research questions that foregrounds the researcher's preference, leads to the methodological decisions, indicate who is spoken to, how the design is executed and how to report the outcomes. Qualitative and quantitative methods offer different and arguably complementary purposes to understanding a specific phenomenon; privileging one paradigmatic orientation over another does not enable a full appreciation and understanding of the lived realities of health care. While EBM has led to positive changes in maternity care, a purely scientific positivistic approach in how care is delivered and evaluated can lead to women feeling objectified and silenced from their maternity encounters. If the goal is to come to a deeper understanding of maternity, or indeed, any area of health care, then hermeneutic phenomenology offers an invaluable means to appreciate women's experiences and to inform and transform care delivery via emancipatory praxis.

\section{References}

Alfirevic, Z., Gyte, G.M.L., Cuthbert, A. \& Devane, D. (2017). Continuous cardiotocography (CTG) as a form of electronic fetal monitoring (EFM) for fetal assessment during labour. The 
460 Cochrane Database of Systematic Reviews, 2. CD006066,

461 doi:10.1002/14651858.CD006066.pub3.

462

Anderson, A. (2013). Ten years of maternity claims: an analysis of the NHS Litigation Authority data - key findings. Journal of Patient Safety and Risk Management, 23(1) doi:10.1177/1356262213486434

Basevi, V., \& Lavender, T. (2014). Routine perineal shaving on admission in labour. The Cochrane Database of Systematic Reviews, 11, doi:10.1002/14651858.CD001236.pub2

Bastian, H., Glasziou, P. \& Chalmers, I. (2010). Seventy-Five Trials and Eleven Systematic

Reviews a Day: How Will We Ever Keep Up? PLOS Medicine, 7:9, doi:10.1371/journal.pmed.1000326

Berg, M. (2000). Guidelines, professionals and the production of objectivity: Standardisation and the professionalism of insurance medicine. Oxford: Blackwell Publishers.

Bohren, M.A., Vogel, J.P., Hunter, E.C, Lutsiz, O., Mahk, S.K., Souza, J.P., Agular, C., Coneglian, F.S., Diniz, A.L.A., Tuncalp, O., Javadi, D., Oladapo, O.T., Khosla, R., Hindin, M.J. \& Gulmezoglu, A.M. (2015) The mistreatment of women during childbirth in health facilities globally: a mixed-methods systematic review. PLOS Medicine, 12:6, doi:10.1371/journal.pmed.1001847

482

Bramadat, I.J., \& Driedger, M. (1993). Satisfaction with childbirth: theories and methods of 484 measurement. Birth, 20(1), 22-29.

Bryman, A. (2016). Social Research Methods. London: Oxford University Press.

Choi, B.C.K. \& Pak, A.W.P. (2005). A catalog of biases in questionnaires. Preventing Chronic 
494 Crouch, M. \& McKenzie, H. (2006) The logic of small samples in interview-based qualitative

Crowther, S. (2017). Birth as sacred celebration. In: Crowther, S. \& Hall, J. (eds) Spirituality and Childbirth: Meaning and Care at the Start of Life (p.13-29). London: Taylor \& Francis.

Crowther, S., Ironside, P., Spence, D. \& Smythe, L. (2016). Crafting Stories in Hermeneutic

Phenomenology Research: A Methodological Device. Qualitative Health Research, 27(6), doi:10.1177/1049732316656161

503

Dahlberg, U. \& Aune, I. (2013). The woman’s birth experience-The effect of interpersonal relationships and continuity of care. Midwifery 29, 407-415.

Doi, S.A.R. (2012). Understanding evidence in health care: Using clinical epidemiology.

Downe, S., Finlayson, K., Tuncalp, Ö. \& Gülmezoglu, A.M. (2016). What matters to women: a systematic scoping review to identify the processes and outcomes of antenatal care provision that are important to healthy pregnant women. BJOG: An International Journal of Obstetrics \& Gynaecology, 123, 529-539, doi:10.1111/1471-0528.13819

Eddy, D.M. (1990). Practice Policies - Where Do They Come from? Journal of the American Medical Association, 263(9), 1265-1275. doi:10.1001/jama.1990.03440090103036

Elmir, R., Schmied, V., Wilkes, L. \& Jackson, D. (2011). Women's perceptions and experiences of a traumatic birth: A meta-ethnography. Journal of Advanced Nursing, 66(10),

523 Enkin, M.W., Glouberman, S., Groff, P, Jadad, A.R. \& Stern, A. (2006). Beyond Evidence: 524 The Complexity of Maternity Care. Birth, 33(4), 265-269, doi:10.1111/j.1523525 536X.2006.00117.x 
527 Epstein, D. (2017). When Evidence Says No, But Doctors Say Yes. Retrieved 6 May 2019

Gadamer, H.G. (1967/2008). Philosophical hermeneutics. London: University of California Press.

Green, J.M., Coupland, V.A. \& Kitzinger, J.V. (1990). Expectations, experiences and psychological outcomes of childbirth: A prospective study of 825 women. Birth, 17(1), 1524.

536

Greenhalgh, T., Howick, J. \& Maskrey, N. (2014). Evidence based medicine: a movement in crisis? BMJ, 348 doi: 10.1136/bmj.g3725

Greenhalgh, T., Snow, R., Ryan, S., Rees, S. \& Salisbury, H. (2015). Six 'biases' against patients and carers in evidence-based medicine. BMC Medicine, 13:200 doi:10.1186/s12916015-0437-x

543

Greenhalgh, T. (1997). How to read a paper. Getting your bearings (deciding what the paper is about). BMJ, 315 doi:10.1136/bmj.315.7102.243.

Grobbee, D.E. \& Hoes, A.W. (2009). Clinical Epidemiology: Principles, Methods, and Applications for Clinical Research. London: Jones \& Bartlett Learning.

Heidegger, M. (1927/1962). Being and time. New York: Harper.

551

Heidegger, M. (1971/2001). Poetry, language, thought. New York: HarperCollins.

Heidegger, M. (1977). Science and Reflection. The question concerning technology and other essays. New York: Garland Publishing.

556

557 Homer, C., Brodie, P., Sandall, J. \& Leap, N. (2019). Midwifery continuity of care: Second 558 Edition. London: Elsevier. 
560 Ioannidis, J.P.A. (2005). Why Most Published Research Findings Are False. PLOS Medicine,

Institute of Medicine (2011). Clinical Practice Guidelines We Can Trust. Retrieved 15 April from:http://www.nationalacademies.org/hmd/ /media/Files/Report\%20Files/2011/ClinicalPractice-Guidelines-We-Can-

Trust/Clinical\%20Practice\%20Guidelines\%202011\%20Report\%20Brief.pdf

Kaelin, E.F. (1988). Heidegger's Being and Time: A Reading for Readers. University Presses 569 of Florida: Florida State University Press.

570

Katz, D.L. (2001). Clinical Epidemiology \& Evidence-Based Medicine: Fundamental Principles of Clinical Reasoning \& Research. London: Sage.

573

574 Kennedy, H.P., Cheyney, M., Dahlen, H.G., Downe, S., Foureur, M.J., Homer, C., Jefford, E., 575 McFadden, A., Michel-Schuldt, M., Sandall, J., Hora, S., Speciale, A.M., Stevens, J., doi:10.1111/birt.12361

Kitzinger, S. (2005). The politics of birth. London: Elsevier.

Krauss, A. (2018). Why all randomised controlled trials produce biased results. Annals of

Kvale,S. \& Brinkman, S. (2009). InterViews: Learning the craft of qualitative research interviewing, London: Sage Publications. 
591 Miller, S., Abalos, E., Chamillard, M., Ciapponi, A., Colaci, D., Comandé, D., Diaz, V., 592 Geller, S., Hanson, C., Langer, A., Manuelli, V., Millar, K., Morhason, B.I., Castro, C.P., 593 Pileggi,V.N., Robinson, N., Skaer, M., Souza, J.P., Vogel, J.P. \& Althabe, F. (2016) Beyond 594 too little, too late and too much, too soon: a pathway towards evidence-based, respectful 595 maternity care worldwide. The Lancet 388, 2176-2192.

596

597 Mullen, E. \& Streiner, D.L.(2004). The Evidence For and Against Evidence-Based Practice. 598 Brief Treatment and Crisis Intervention 4(2),111-121, doi:10.1093/brief-treatment/mhh009 599

600 Paley, J. (2005). Phenomenology as rhetoric. Nursing Inquiry, 12, 106-116, 601 doi:10.1111/j.1440-1800.2005.00263.x.

602

603 Paley, J. (2016). Phenomenology as qualitative research: A critical analysis of meaning 604 attribution. London: Routledge.

605

606

Patterson, J. (2018). Understanding the needs of women and midwives as they interact during 607 maternity care provision. Practising Midwife, (March), 38-42.

608

Patterson, J. (2019). Traumatised Midwives; Traumatised Women. AIMS, 30(4) Retrieved 19 May 2019 from: https://www.aims.org.uk/journal/item/traumatised-midwives-traumatisedwomen?fbclid=IwAR3VYKmRNTJ7Johh4fX9DMCb05_oEGE3WQJ_pdDOhEeJzqaLgQ88 rabKmew

613

614

Patton, M.Q. (2014). Qualitative Research \& Evaluation Methods: Integrating Theory and 615 Practice. Saint Paul, MN, USA: Sage.

616

Plager, K.A. (1994). Hermeneutic phenomenology: A methodology for family health and 618 health promotion study in nursing. In P. Benner, Interpretive Phenomenology: Embodiment, 619 Caring \& Ethics in Health and Illness (p.65-83). Thousand Oaks, California: Sage. 620 Prakash, B. (2010). Patient Satisfaction. Journal of Cutaneous and Aesthetic Surgery, 3(3), 151-155. 
624 Proctor, S. (1999). Women's reactions to their experience of maternity care. British Journal of Midwifery, 7(8), 492-498. doi:10.12968/bjom.1999.7.8.8284

626

627

Reveiz, L., Gaitán, H.G. \& Cuervo, L.G. (2013) Enemas during labour. The Cochrane

Database of Systematic Reviews, 7. CD000330. doi:10.1002/14651858.CD000330.pub4.

629

630

Rogers, W.A. (2004). Evidence based medicine and justice: a framework for looking at the impact of EBM upon vulnerable or disadvantaged groups. Journal of Medical Ethics, 30(2), 141-145.

633

Sackett, D.L., Rosenberg, W.M., Gray, J.A., Haynes, R.B. \& Richardson, W.S. (1996).

Evidence based medicine: what it is and what it isn't BMJ, 312(7023), 71-72. doi:10.1136/bmj.312.7023.71.

637

638

Salmon, P. \& Drew, N.C. (1992). Multidimensional assessment of women's experience of 639 childbirth: Relationship to obstetric procedure, antenatal preparation and obstetric history. Journal of Psychosomatic Research, 36(4), 317-327, doi:10.1016/0022-3999(92)90068-D

641 models versus other models of care for childbearing women. Cochrane Database of Systematic Reviews, 4 CD004667, doi:10.1002/14651858.CD004667.pub5.

Sawyer, A, Ayers, S., Abbott, J., Gyte, G., Rabe, H. \& Duley, L. (2013) Measures of 647 satisfaction with care during labour and birth: a comparative review. BMC Pregnancy and Childbirth, 13:108, doi: 10.1186/1471-2393-13-108

Scottish Government (2019). Maternity care survey 2018: national results. Retrieved 16 April 2019 from: https://www.gov.scot/publications/maternity-care-survey-2018-national-results/ 
656 Sitzia, J. \& Wood, N. (1997). Patient satisfaction: a review of issues and concepts. Social

657 Science \& Medicine, 12, 1829-1843, doi:10.1016/S0277-9536(97)00128-7

658

659

Smythe E. (2011). From beginning to end: how to do hermeneutic interpretive 660 phenomenology. In: Thomson, G., Dykes, F. \& Downe, S. (eds). Qualitative research in 661 midwifery and childbirth: Phenomenological approaches (p.35-44). London: Routledge.

662

663 Smythe E, Hunter M, Gunn J, Crowther, S., McAra Couper, J., Wilson, S. \& Payne, D. (2016) 664 Midwifing the notion of a 'good' birth: a philosophical analysis. Midwifery 37, 25-31, doi: $665 \quad \underline{10.1016 / j . m i d w .2016 .03 .012 ~}$

666

667

Spiegelhalter, D. (2019). The Art of Statistics: Learning from Data. London: Penguin Books 668 Limited.

669

670

Straus, S.E., \& McAlister, F.A. (2000). Evidence-based medicine: a commentary on common

671

criticisms. Canadian Medical Association Journal, 163(7), 837-841, doi:

672 $\underline{10.1080 / 01674820802545453}$

673

674

Timmermans S, Mauck A (2005). The promises and pitfalls of evidence-based medicine. 676

677

678 Health Affairs, 24(1), 18-28. doi:10.1377/hlthaff.24.1.18. PMID 15647212.

679 273.

680

681

682

van Manen, M. (2014). Phenomenology of Practice: Meaning-Giving Methods in Phenomenological Research and Writing. California: Left Coast Press.

683

684

685

Weisz, G., Cambrosio, A., Keating, P., Knaapen, L., Schlich, T., \& Tournay, V. (2007). The emergence of clinical practice guidelines. The Milbank Quarterly, 85(4), 691-727. 686 doi:10.1111/j.1468-0009.2007.00505.x

687 
688 Wieringa, S., Engebretsen, E., Heggen, K. \& Greenhalgh, T. (2017). Has evidence -based

689 medicine ever been modern? A Latour

förspialed understandin

690 of Evaluation in Clinical Practice, 23(5), doi: 10.1111/jep.12752

691

692 Wolf, N. (2001). Misconceptions; truth, lies, and the unexpected on the journey to motherhood, 693 New York: Doubleday.

694

695 World Health Organisation (2018). WHO recommendations: Intrapartum care for a positive 696 childbirth experience. Geneva: World Health Organization.

697

698

699

700

701

702

703

704

705

706 